\title{
The Relationship among Ligand Conformations in Solution, in the Solid State and at the Hsp90 Binding Site; Geldanamycin and Radicicol
}

\author{
Pahk Thepchatri, Tomasso Eliseo, Daniel O. Cicero, David Myles, \\ and James P. Snyder
}

Complete ref 25: Wright, L.; Barril, S.; Dymock, B.; Sheridan, L.; Surgenor, A.; Beswick, M.; Drysdale, M.; Collier, A.; Massey, A.; Davies, N.; Fink, A.; Fromont, C.; Aherne, W.; Boxall, K.; Sharp, S.; Workman, P.; Hubbard, R. E. Chem.E Biol. 2004, 11, 775-785.

Complete ref 30b: Fesik, S. W.; Gampe, R. T. Jr.; Eaton, H. L.; Gemmecker, G.; Olejniczak, E. T.; Neri, P.; Holzman, T. F.; Egan, D. A.; Edalji, R.; Simmer, R.; Helfrich, R.; Hochlowski, J.; Jackson, M. Biochemistry 1991, 30, 6574-6583.

Complete ref 50: Frisch, M. J.; Trucks, G. W.; Schlegel, H. B.; Scuseria, G. E.; Robb, M. A.; Cheeseman, J. R.; Montgomery, J. A.; Vreven, T.; Kudine, K. N.; Burant, J. C.; Millam, J. M.; Iyengar, S. S.; Tomasi, J.; Barone, V.; Mennucci, B.; Cossi, M.; Scalmani, G.; Gega, N.; Petersson, G. A.; Nakatsji, H.; Hada, M.; Ehara, M.; Toyota, K.; Fukuda. R.; Hasegawa, J.; Ishida, M.; Nakajima, T.; Honda, Y.; Kitao, O.; Nakai, H.; Kelene, M.; Li, X.; Know, J. E.; Hratchian, H. P.; Cross, J. B.; Bakken, V.; Adamo, C.; Jaramillo, J.; Gomperts, R.; Stratmann, R. E.; Yazyev, O.; Austin, A. J.; Cammi, R.; Pomelli, C.; Ochterski, J. W.; Ayala, P. Y.; Morokuma, K.; Voth, G. A.; Salvador, P.; Dannenberg, J. J.; Zakrzewski, V. G.; Dapprich, S.; Daniels, A. D.; Strain, M. C.; Farkas, O.; Malick, D. K.; Rabuck, A. D.; Raghavachari, K.; Foresman, J. B.; Ortix, J. V.; Cui, Q.; Baboul, A. G.; Glifford, S.; Cioslowski, J.; Stefanov, B. B.; Liu, G.; Liashenko, A.; Piskorz, P.; Komaromi, I.; Martin, R. L.; Fox, D. J.; Keith, T.; Al-Laham, M. A.; Peng, C. Y.; Nanayakkara, A.; Challacombe, M.; Gill, P. M. W.; Johnson, B.; Chen, W.; Wong, M. W.; Gonzalez, C.; Pople, J. A., Gaussian 03, Revision C.02. 2004, Gaussian, Inc.: Wallingford, CT. 